\title{
Potential Ameliorative Effect of Bee Honey on Experimentally Induced Melamine Formaldehyde Toxicity in Male Rats
}

\author{
Ahlam Farouk Hamouda ${ }^{1}$, Aziza Abd Elfattah Amin², Samar Saber Ibrahim ${ }^{1}$, and Mohamed Abdelaziz Mahmoud ${ }^{3 *}$ \\ ${ }^{I}$ Department of Forensic Medicine and Toxicology, Faculty of Veterinary Medicine, Benha University, Egypt \\ ${ }^{2}$ Department of pathology, Faculty of Veterinary Medicine, Benha University, Egypt \\ ${ }^{3}$ Department of Physiology, Faculty of Veterinary Medicine, New Valley University, Egypt \\ *Corresponding author's email: Barhoma_56@aun.edu.eg ; ORCID: 0000-0002-2637-1542
}

\begin{abstract}
Melamine is considered as one of urea derivatives. Recently it is added to feed stuffs for industrial purposes (falsely elevate its protein contents), however addition of melamine resulted in marked oxidative stress and toxic effect on different body organs, especially the nephrotoxicity and urolithiasis. Therefore, this work is designed to explore the beneficial effect of bee's honey to alleviate the harmful effect induced by melamine toxicity and to show the histological changes on male albino rats. In this work seven animal groups (five rats for each), group 1; negative control, while groups 2, 4, 6 received melamine-formaldehyde orally at dose $0.9,90,9000 \mathrm{ppm}$, respectively while groups 3, 5,7 received the same melamine dose beside bee's honey (dose of $2.5 \mathrm{gm} / \mathrm{kg}$ body weight (B. w) for 45 days. Results declared that melamine treated rats showed marked oxidative, biochemical, hematological changes as well as pathological alterations in vital assets especially liver and urinary system. As distension of the urinary bladder, crystals deposition and stone formation were detected with variable degrees in all groups treated only with melamine. Microscopically, various pathological changes in kidneys, liver, lung, heart and intestine were also demonstrated. The severity of these changes varied from mild to severe changes depending upon the dose of melamine. Interestingly, rats treated with melamine plus the bee's honey showed mild changes in comparison to the only melamine treated rats. These findings assured that, marked antioxidant and ameliorative effect of bee's honey successfully reduced the noxious effect of melamine on different body organs.
\end{abstract}

Key words: Melamine, Vital assets toxicity, Bee's honey, White albino rats

\section{INTRODUCTION}

Recently milk was supplemented with melamine for false elevation of its protein contents, melamine is liquefied in water without forming precipitate as well as its solubility increases at elevated temperature, these facts make it is possible to add excessive amount of melamine that can be dissolved in warm water, the addition of melamine to milk in dose of $1 \mathrm{~g}$ per $1 \mathrm{~L}$ falsely elevates the protein content by $0.4 \%$ (Hau et al., 2009). Melamine accepted human oral dose is $0.2 \mathrm{mg} / \mathrm{kg}$ body weight/day (Zhang et al., 2009). In March 2007, several cases of acute renal dysfunction were reported in cats and dogs ingested food contaminated with melamine, it became a discussion topic when, melamine contamination of pet's food had led to hundreds of deaths ( $\mathrm{Li}$ et al., 2010). More over by September 2008, melamine was illegally contaminated in infant formulas which caused thousands of deaths in china children (Zhang et al., 2009). Melamine contaminated tainted products consumption had led to children several cases of renal complications (Chan et al., 2008; Filigenzi et al., 2008). Contamination of milk-derived products was detected in China (Bhalla et al., 2009). Animal's study showed that rats treated with melamine showed listlessness, anorexia, loss in condition, decreased body weight, reduced litter size, and average fetal body weight (Stine et al., 2014), toxic influence on hippocampus and causes impairments of synaptic plasticity (An et al., 2011). Stones formation were the most prominent findings in majority of subacute and chronic melamine exposure (Hau et al., 2009). According to gender, melamine doses and amount of water intake the incidence varied from 5 to 100\% (Ogasawara et al., 1995). The stones composition is either a mixture of uric acid and melamine or melamine in protein matrix, phosphate and uric acid (Hau et al., 2009). It is a complicated process from crystals to stone formation for all types of stone. Crystals could be excreted with urine flow and would not form stone unless it remains in the kidney tubules (Zhang et al., 2009). In general, renal tubules injury, dysfunction can favor nucleation, aggregation and retention of crystal (Khan, 2006). Several efforts have been done for reducing melamine produced oxidative stress. Honey is formed of a compound mix of proteins, carbohydrates, enzymes (glucose oxidase, catalase, phosphatases and invertase), organic and amino acids (acetic acid, gluconic acid, etc.), vitamins, lipids (pyridoxine, niacin, ascorbic acid, catalase, tocopherols, and phenolic compounds), phenolic acids, volatile chemicals, flavonoids, minerals and carotenoidlike materials that possess antioxidants properties (Blasa et al., 2006). Honey is a normal antioxidant that eliminating and 
scavenging free radicals (Johnston et al., 2005). Honey possess a protecting role against the sodium nitrite feed additives induced renal malfunction, besides its antioxidant and hepatoprotective effects (Erejuwa et al., 2012). Honey increases the epididymal weight and augments spermatogenesis in male Wistar rats (Abdul-Ghani et al., 2008). Accordingly, the purpose of the current study was to examine the protective effect of the bee's honey on the melamine induced toxicity as well as to illustrate the histopathological changes on vital body assets in male albino rats.

\section{MATERIALS AND METHODS}

\section{Experimental animals}

35 male albino rats weighing 180-200g were used throughout the experiments. The rats obtained from animal house of national research center, Giza, Egypt. The animals were kept in the animal house in the faculty of veterinary medicine, Benha university at $21-22{ }^{\circ} \mathrm{C}$ in a12/12 h light/dark cycle and were allowed free access water and standard food pellets throughout the experimental period. Rats accommodated to the laboratory conditions for two weeks before starting the experiment.

\section{Ethical approval}

All the experiment animals were carried out under the approved protocols by the institutional animal house of faculty of veterinary medicine, Benha, University, Egypt.

\section{Experimental design}

Rats were randomly located into seven groups (five rats each). Group 1 (G1) was kept as a negative control given distilled water only. Group 2 (G2), group 4 (G4) and group 6 (G6) were administered melamine formaldehyde (SigmaAldrich, Germany) orally at doses of 0.9, 90 and 9000 ppm, respectively for 45 days. While, group 3 (G3), group 5 (G5) and group 7 (G7) were treated for the same period, with the same melamine doses (0, 9, 90 and 9000 ppm) plus bee's honey $(2.5 \mathrm{gm} / \mathrm{kg} \mathrm{BW})$, bought from agriculture faculty, Benha University, Egypt. Melamine and bee's honey doses were dissolved in distilled water and given orally using stomach tube in daily basis.

\section{Blood samples collection and analyses}

\section{Hematological parameter evaluation.}

At day 45, two blood samples were collected from retro-orbital venous plexus one sample was collected in EDTA containing tubes for the hematological parameters while the other blood sample was collected without anticoagulant, left in room temperature for 20 minutes then centrifugated for 20 minutes at speed of 3500 (RPM) for serum separation, serum then kept at $-20^{\circ} \mathrm{C}$ and stored to be used in biochemical analysis. Hematological parameters (Table 2), Red Blood Cells (RBC) counts, Packed Cell Volume (PCV), Hemoglobin (Hb), and White Blood Cells (WBC) counts were done according to Feldman and Jain (2000) using a Hema Screen 18 automated hematology analyzer (Hospitex Diagnostics, Sesto Fiorentino, Italy).

\section{Biochemical analysis.}

Separated serum was used for determination of Aspartate Aminotransferase (AST) and Alanine Aminotransferase (ALT) in serum was done according to Reitman and Frankel (1957). Alkaline phosphatase was measured according to Kochmar and Mossa (1976). Creatinine was calculated according to Henry (1974). Urea was measured according to Patton and Crouch (1977) and uric acid was calorimetrically determined according to Morris and Macleod (1922). Sodium $(\mathrm{Na})$, potassium $(\mathrm{k})$ and chlorine $(\mathrm{Cl})$ were determined using Lustgarten et al. (1974) method. Calcium $\left(\mathrm{Ca}{ }^{++}\right)$ was determined following Leary et al. (1992) method, while phosphorus determination was done according to Munoz and Balon (1983).

\section{Redox state evaluation.}

Determination of Glutathione (GSH) in liver tissue homogenate was done using the method ascribed by Beutler (1963). Malondialdehyde was determined calorimetrically according to the method described by Ohkawa et al. (1979) and Catalase was measured using Hadwan (2016).

\section{Histopathological examination.}

Small tissue specimens from liver, kidneys, heart, intestine and lungs of rats in different groups were taken at 45 days and immediately fixed in $10 \%$ neutral buffered formalin. Following to proper fixation, samples were dehydrated using ethyl alcohol, then cleared in xylol, embedded and casted in paraffin. According to Suvarna et al. (2018), preparation of thin paraffin sections, staining with Hematoxylin and Eosin stain was done. 


\section{Statistical analysis}

SPSS (version 20, USA) was used for the statistical analysis. Data were evaluated using one-way ANOVA, followed by Duncan's test. Results expressed as means \pm S.E. Accepted significant values were $\mathrm{P}<0.05$.

\section{RESULTS}

\section{Clinical signs}

No clinical signs appeared, except in the last week that two animals from G6 have died, but before death these animals showed some sort of convulsions and diarrhea (Figure 1a).

\section{Postmortem examination}

Postmortem changes (G6) were represented in congested intestine, distended urinary bladder with urine (Figure $1 b$ ), with accumulation of white crystals in the two ureters (Figure 1c).

\section{Redox state}

Concerning changes in the hepatic tissue reduced GSH and malondialdehyde level, there were significant increase $(\mathrm{P}<0.05)$ in all melamine treated groups $(\mathrm{G} 4$ and $\mathrm{G} 6)$ compared to the control negative group $(\mathrm{G} 1)$, however, these elevations were lesser in G2. Meanwhile, a significant decrease $(\mathrm{P}<0.05)$ of reduced GSH and GSH in bee's honey treated groups (G3, G5 and G7) in comparison to only melamine treated groups (Table 1). While, concentration of tissue catalase was significantly $(\mathrm{P}<0.05)$ increased in the melamine treated groups than negative control group however there was no significant $(\mathrm{P}<0.05)$ variation among the only melamine treated groups $(\mathrm{G} 2$, G4 and $\mathrm{G} 6)$ and melamine plus bee's honey treated groups (G3, G5 and G7).

\section{Hematological parameter evaluation}

Regarding RBCs counts and its related parameters HB and PCV \% among examined groups, there was a significant decrease $(\mathrm{P}<0.05)$ in only melamine fed groups $(\mathrm{G} 2, \mathrm{G} 4$ and G6) compared to control group. Conversely, the melamine and bee's honey fed groups $(\mathrm{G} 3, \mathrm{G} 5$ and G7) showed non-significant decrease $(\mathrm{P}<0.05)$ in $\mathrm{RBCs}$ counts and other related parameters compared to control group. Generally, there was an inverse correlation between melamine dose and RBCs count, $\mathrm{Hb}$ and $\mathrm{PCV} \%$ (Table 2). In respect to $\mathrm{WBC}$ a significant reduction $(\mathrm{P}<0.05)$ has been observed in groups G4 and G6 compared to the control one. Though the bee's honey treated groups (G3, G5 and G7) showed significant increase $(\mathrm{P}<0.05$; Table 2$)$ in the WBCs than the only melamine treated groups $(\mathrm{G} 2, \mathrm{G} 4$ and $\mathrm{G} 6)$.

Table 1. Enzymatic changes among different melamine doses and honey feed groups in male rats

\begin{tabular}{lccc}
\hline Groups & $\begin{array}{c}\text { Reduced glutathione } \\
\text { Mg/gm tissue (Mean } \pm \text { SE) }\end{array}$ & $\begin{array}{c}\text { MDH nmol/gm tissue } \\
(\text { Mean } \pm \text { SE) }\end{array}$ & $\begin{array}{c}\text { Catalase U/gm tissue } \\
(\text { Mean } \pm \text { SE) }\end{array}$ \\
\hline Group 1 & $13.04 \pm 0.61^{\mathrm{d}}$ & $1394.42 \pm 46.63^{\mathrm{g}}$ & $201.63 \pm 13.97^{\mathrm{d}}$ \\
Group 2 & $17.68 \pm 0.36^{\mathrm{c}}$ & $2411.45 \pm 80.08^{\mathrm{e}}$ & $375.58 \pm 12.96^{\mathrm{c}}$ \\
Group 3 & $15.99 \pm 0.16^{\mathrm{c}}$ & $1989.00 \pm 77.96^{\mathrm{f}}$ & $376.73 \pm 13.10^{\mathrm{c}}$ \\
Group 4 & $25.11 \pm 0.64^{\mathrm{b}}$ & $3389.95 \pm 163.70^{\mathrm{c}}$ & $433.17 \pm 2.90^{\mathrm{b}}$ \\
Group 5 & $21.28 \pm 0.75^{\mathrm{bc}}$ & $2906.58 \pm 27.43^{\mathrm{d}}$ & $418.44 \pm 4.88^{\mathrm{b}}$ \\
Group 6 & $61.20 \pm 8.53^{\mathrm{a}}$ & $4975.82 \pm 264.88^{\mathrm{a}}$ & $489.22 \pm 8.58^{\mathrm{a}}$ \\
Group 7 & $31.43 \pm 2.27^{\mathrm{b}}$ & $4307.87 \pm 61.05^{\mathrm{b}}$ & $465.32 \pm 2.98^{\mathrm{a}}$ \\
\hline
\end{tabular}

Mean label different superscripts (abcd...) letters at the same column are significantly different at $\mathrm{P}<0.05$. MDH: malondialdehyde. Group 1 is negative control, groups 2, 4, and 6 received melamine at dose of $0.9,90$ and 9000 ppm respectively while groups 3, 5, 7 received melamine in dose of $0.9,90$ and $9000 \mathrm{ppm}$ beside $2.5 \mathrm{gm} / \mathrm{kg} \mathrm{B.W}$

Table 2. Hematological changes among different melamine doses and honey treated male rat's groups

\begin{tabular}{lcccc}
\hline Groups & $\begin{array}{c}\text { RBCS }\left(\times \mathbf{1 0}^{\mathbf{6}} / \boldsymbol{\mu L}\right) \\
(\text { Mean } \pm \mathbf{S E})\end{array}$ & $\begin{array}{c}\text { TLC }\left(\times \mathbf{1 0}^{\mathbf{3}} \boldsymbol{\mu L}\right) \\
(\mathbf{M e a n} \pm \mathbf{S E})\end{array}$ & $\begin{array}{c}\text { Hb }(\mathbf{g m} / \mathbf{d l}) \\
(\mathbf{M e a n} \pm \mathbf{S E})\end{array}$ & $\begin{array}{c}\text { PCV\% } \\
(\mathbf{M e a n} \pm \mathbf{S E})\end{array}$ \\
\hline Group 1 & $6.72 \pm 0.20^{\mathrm{a}}$ & $9.91 \pm 0.17^{\mathrm{a}}$ & $13.95 \pm 0.26^{\mathrm{a}}$ & $41.28 \pm 0.33^{\mathrm{a}}$ \\
Group 2 & $6.30 \pm 0.11^{\mathrm{b}}$ & $6.84 \pm 0.12^{\mathrm{c}}$ & $9.98 \pm 0.30^{\mathrm{c}}$ & $38.47 \pm 0.64^{\mathrm{bc}}$ \\
Group 3 & $6.71 \pm 0.04^{\mathrm{a}}$ & $8.11 \pm 0.48^{\mathrm{b}}$ & $11.74 \pm 0.30^{\mathrm{b}}$ & $41.00 \pm 0.24^{\mathrm{a}}$ \\
Group 4 & $6.32 \pm 0.06^{\mathrm{b}}$ & $5.88 \pm 0.17^{\mathrm{d}}$ & $9.32 \pm 0.32^{\mathrm{c}}$ & $38.60 \pm 0.33^{\mathrm{b}}$ \\
Group 5 & $6.72 \pm 0.05^{\mathrm{a}}$ & $7.76 \pm 0.17^{\mathrm{bc}}$ & $9.74 \pm 0.25^{\mathrm{c}}$ & $41.02 \pm 0.27^{\mathrm{a}}$ \\
Group 6 & $5.91 \pm 0.07^{\mathrm{c}}$ & $2.63 \pm 0.58^{\mathrm{e}}$ & $5.56 \pm 0.90^{\mathrm{e}}$ & $36.07 \pm 0.46^{\mathrm{d}}$ \\
Group 7 & $6.11 \pm 0.08^{\mathrm{bc}}$ & $5.13 \pm 0.30^{\mathrm{d}}$ & $7.44 \pm 0.71^{\mathrm{d}}$ & $37.30 \pm 0.51^{\mathrm{c}}$ \\
\hline
\end{tabular}

Means label different superscripts (abcd...) letters at the same column are significantly different at P<0.05. RBCS: erythrocyte counts, TLC: Total leucocyte counts, $\mathrm{Hb}$ : hemoglobin, PCV: packed cell volume, Group1 is negative control, groups 2, 4, and 6 received melamine at dose of $0.9,90$ and $9000 \mathrm{ppm}$ respectively while groups $3,5,7$ received melamine in dose of $0.9,90$ and $9000 \mathrm{ppm}$ beside $2.5 \mathrm{gm} / \mathrm{kg} \mathrm{B.W}$ 


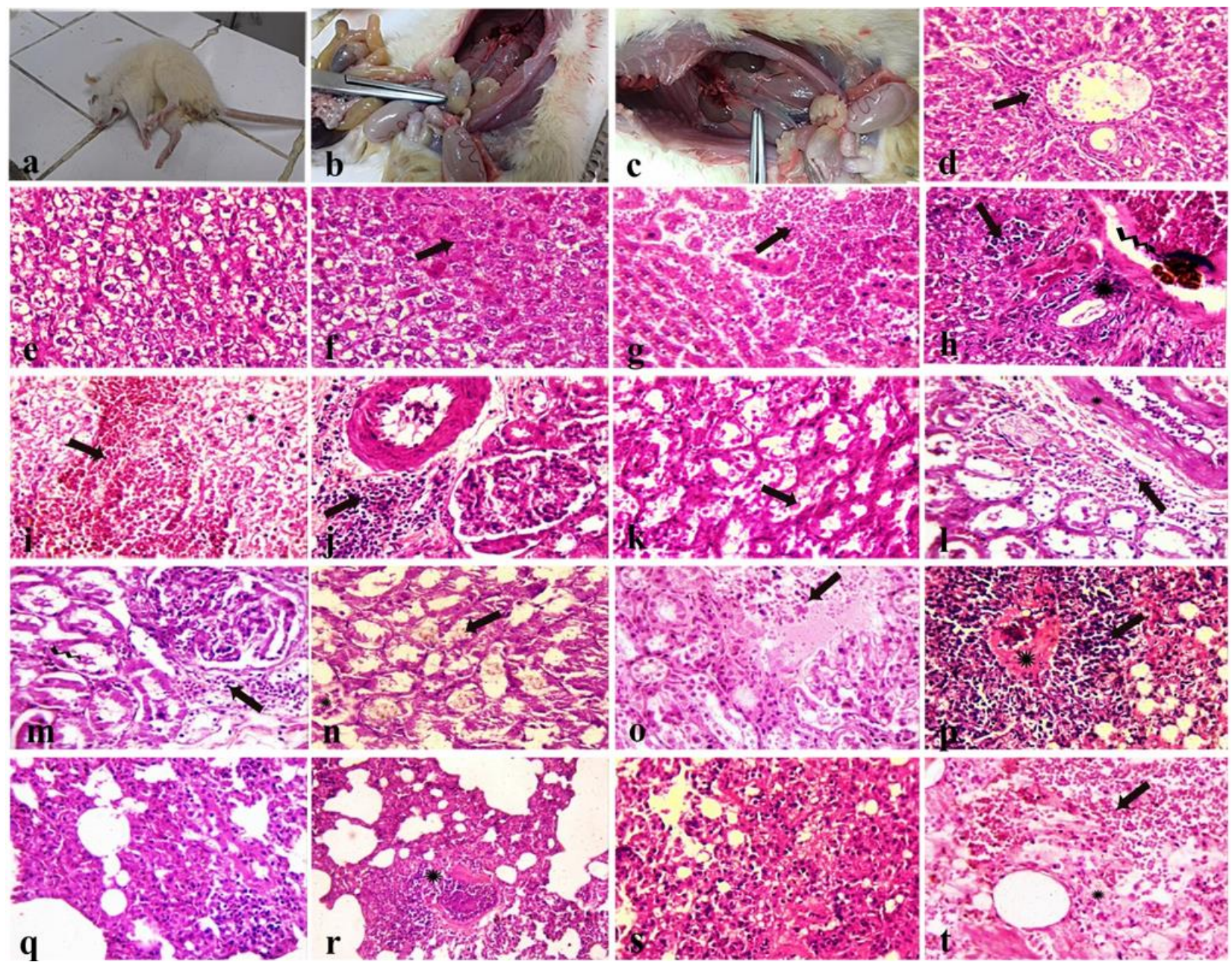

Figure 1. Postmortem changes and changes among different organs of male rats treated with different melamine concentration and bee's honey. Convulsion (a), urinary bladder distension with urine and crystals (b), distension in ureter with crystals (c) stained sections with H \& E. liver obtained from group 2 (d and e), group 4 (f and $\mathbf{g})$ and group 6 (h and i), d: showing congestion of portal blood vessels with mild mononuclear leukocytic cellular infiltration (arrow, x 400), e: Diffuse hydropic degeneration of hepatocytes in the hepatic parenchyma (x 200), f: Focal area of coagulative necrosis in the hepatic parenchyma (arrow, x 200), g: Area of lytic necrosis in the hepatic parenchyma that characterized by disappearance of hepatocytes and replaced by erythrocytes and eosinophilic necrotic debris (arrow, x 200), h: Moderate proliferation of the biliary epithelium (asterisk) with mild mononuclear leukocytic cellular infiltration (arrow, x200), with accumulation of melamine substance in the portal blood vessels (zigzag arrow, x 200), i: Extensive lytic necrosis scattered in the hepatic parenchyma (arrow) with marked hydropic degeneration in the remnant hepatocytes (asterisk, $\mathrm{x}$ 200). Renal changes stained sections with H\&E for group 2 (j and $\mathbf{k}$ ) group 4 (l and $\mathbf{m}$ ) and group 6 (n and $\mathbf{o}$ ) taken from animals treated with different concentrations of melamine, perivascular edema admixed with mononuclear leukocytic infiltration (arrow, x200) with vacuolar degeneration of mesangial cells of glomeruli (j) (x 200), k: Necrosis of the lining epithelium of renal tubules with the presence of hyaline casts in the lumen of some renal tubules (arrow, x 200), m: Degenerative changes in the wall of renal blood vessels (asterisk) with perivascular edema admixed with inflammatory cells (arrow) with marked necrosis of the epithelial cell lining of renal tubules (1). Necrosis of the endothelial cell lining of the glomerular tuft with peri-glomerular leukocytic infiltration (arrow) with necrotic eosinophilic debris in the lumen of some renal tubules (zigzag arrow, x 200), n: Entire necrosis of the glomerular tuft (asterisk) and the lining epithelium of renal tubules with accumulation of melamine substance in the lumen of some renal tubules (arrow, x 200), o: Focal areas of lytic necrosis that characterized by disappearance of renal tissues and replaced by proteinaceous eosinophilic substance with necrotic debris (arrow, x 200). Pulmonary changes stained sections of lung with H\&E in group 2 (p and $\mathbf{q})$, group 4 (r and s) and group $6(\mathbf{t})$. p: Peri-vascular edema admixed with mononuclear leukocytic cellular infiltration (arrow, x200), with hyalinization of the wall of pulmonary blood vessels (asterisk, x200), q: Diffuse alveolar consolidation (arrow) filed with eosinophilic exudate with inflammatory cells and alternated with emphysema (x 200), r: Rupture of the wall of pulmonary blood vessels (asterisk, x200) with consolidated alveoli (x 200), s: Diffuse alveolar consolidation of most pulmonary alveoli (x 200), t: Diffuse hemorrhage in pulmonary tissue (arrow, x200), with distension of pulmonary alveoli with edematous eosinophilic substances (asterisk, x200).

\section{Biochemical analysis \\ Kidney function.}

Parameters assessing the kidney function Blood Urea Nitrogen (BUN), creatinine, uric acid] showed a significant $(\mathrm{P}<0.05)$ serum elevation (Table 3) in all melamine treated groups (G2, G3, G4, G5, G6 and G7) than control group (G1). Although the bee's honey treated groups (G3, G5 and G7) showed significant reduction $(\mathrm{P}<0.05)$ in the serum level of these parameters than the only melamine treated groups with the same doses, respectively (G2, G4 and G6).

\section{Liver function.}

It was observed that the liver function assessing factors (AST, ALT and total protein) showed marked changes. About serum level of both AST and ALT, it showed significant increases $(\mathrm{P}<0.05)$ in the melamine treated groups $(\mathrm{G} 4$, 
G6 and G7), while the melamine plus bee's honey treated groups (G3, G5 and G7) showed a significant reduction $(\mathrm{P}<0.05)$ than the melamine treated groups $(\mathrm{G} 2, \mathrm{G} 4$ and $\mathrm{G} 6)$. Concerning serum total protein, the melamine treated groups showed a significant reduction $(\mathrm{P}<0.05)$ than control one, however the melamine plus bee's honey treated groups showed a significant increase $(\mathrm{P}<0.05)$ than only melamine treated groups.

\section{Electrolyte state evaluation.}

A significant decrease $(\mathrm{P}<0.05)$ in serum electrolytes levels (Table 4) was indicated in all treated groups compared to the control group, the melamine treated groups (G2, G4 and G6) caused a significant decrease $(P<0.05)$ in the electrolytes level than the melamine plus bee's honey groups (G3, G5 and G7).

\section{Histopathological changes.}

Various degrees of pathological alterations were demonstrated in different investigated organs mainly in rats that have high concentrations of melamine (G4 and G6). Animals received melamine at concentration of 0.9 ppm (G2) revealed marked congestion of central vein, blood sinusoids and portal blood vessels with mild perivascular mononuclear leukocytic cellular infiltration (Figure 1d), mild hyperplastic proliferation of biliary epithelium with formation of newly formed bile ductless as well as periductal mononuclear inflammatory cells were seen in most treated animals. Enlarged hepatocytes, with diffuse hydropic degeneration was observed (Figure 1e). Small focal areas of coagulative necrosis of hepatocytes, characterized by retention of hepatic cell outline with hypereosinophilic cytoplasm of hepatocytes and karyorrhectic nuclear changes. Equally, marked congestion of hepatic blood vessels with biliary epithelium hyperplasia was seen in G4. Additionally, extensive hydropic degeneration associated with pyknosis of the nuclei of individual hepatocytes as well as multiple focal areas of coagulative necrosis was demonstrated in G4 (Figure 1f). Scattered area of lytic necrosis in the hepatic parenchyma that characterized by disappearance of hepatocytes and replaced by erythrocytes and eosinophilic necrotic debris (Figure $1 \mathrm{~g}$ ) was also detected. Meanwhile, moderate proliferation of the biliary epithelium with mild mononuclear leukocytic cellular infiltration with accumulation of melamine substance in the portal blood vessels (Figure 1h) was detected in the liver tissue obtained from G6. Furthermore, scattered hemorrhagic areas with multiple area of lytic necrosis (Figure 1i) that characterized by disappearance of hepatocytes and replaced by erythrocytes with marked hydropic degeneration in the remnant hepatocytes was seen in the hepatic parenchyma of treated rats of G6. The microscopical examination of kidneys revealed perivascular mononuclear cellular infiltration with degeneration in the wall of the renal blood vessels (Figures $1 \mathrm{j}$ and $1 \mathrm{~L}$ ) that characterized by hyperplasia of its endothelial cell lining with vacuolation of the sarcoplasm of its muscular layer was detected in all treated groups with different concentrations of melamine (G2, G4 and G6) with variable degree. Moreover, vacuolar degeneration of the endothelial cell lining of the glomerular tuft was demonstrated in rats of G2 (Figure 1j). Additionally, the lining epithelium of proximal and distal convoluted tubules were swollen and exhibited vacuolar and hydropic degeneration. Moreover, the renal tubules in the renal cortex showed coagulative necrosis of their lining epithelium evidenced by hyper-eosinophilic cytoplasm and pyknosis and karyorrhexis of nuclei with homogenous eosinophilic casts were also seen in the lumen of some convoluted tubules (Figure 1k). Moreover, severe degree of degeneration of the lining epithelium of proximal and distal convoluted tubules with periglomerular and perivascular leukocytic cellular infiltration was noticed in G4 (Figures $1 \mathrm{~L}$ and $1 \mathrm{~m}$ ). Meanwhile, severe shrinkage and necrosis of glomerular tuft and the lining epithelium of renal tubules with the presence of hyaline and cellular casts in their lumen in association with accumulation of melamine like substance in the lumen of some renal tubules (Figure 1n). Focal areas of lytic necrosis that characterized by disappearance of renal tissues and replaced by proteinaceous eosinophilic substance with necrotic debris (Figure 1o).

Additionally, marked cystic dilatation of some renal tubules. Periglomerular, perivascular and intertubular leukocytic cellular infiltration was noticed in G6. On the other hand, various pathological changes with different severity were displayed in the lungs of rats fed diet supplemented with different concentrations of melamine (G2, G4 and G6). Congestion of pulmonary blood vessels, perivascular mononuclear inflammatory cells mainly lymphocytes (Figure 1p) was observed in the lungs of groups G2, G4 and G6. Meanwhile, small focal areas of alveolar consolidation that filled with inflammatory exudate composed of fibrin threads admixed with macrophages and lymphocytes (Figure 1q) in association with focal areas of emphysema were demonstrated in rats of G2. On the other side, rupture of the wall of pulmonary blood vessels (Figure 1r) as well as scattered areas of consolidated alveoli with focal areas of atelectasis with compensatory emphysema (Figure 1s) was noticed in lungs of rats of G4. Meanwhile, diffuse hemorrhagic areas in the pulmonary tissue (Figure 1t) with extensive consolidation of pulmonary alveoli was seen in lungs of G6 (Figure 2a). The most common pathological changes in the heart of G2, G4 and G6 were intermuscular hemorrhages (Figure 2b) myocardial degeneration characterized by presence of clear vacuoles in the sarcoplasm of myocardium in combination with hyaline degeneration of myocardium that characterized by highly eosinophilic sarcoplasm with loss of muscular striation (Figures $2 \mathrm{c}$ and 2d). Additionally, extensive degeneration in the wall of myocardial blood vessels was also detected with severe intermuscular hemorrhage (Figure 2e). In the heart of group 6. The intestinal microscopical examination of G2 showed mild desquamation of the lining epithelial cells of the intestinal villi. Accidentally, small necrotic areas represented by more eosinophilic cytoplasm with pyknotic nuclei. 
Table 3. Biochemical changes among different melamine doses and honey treated male rat's groups

\begin{tabular}{|c|c|c|c|c|c|c|}
\hline $\begin{array}{ll}\text { Factors } \\
\text { Groups }\end{array}$ & BUN (mg/dl) & $\begin{array}{c}\text { Creatinine } \\
\text { mg/dl }\end{array}$ & $\begin{array}{l}\text { Uric acid } \\
\text { mg/dl }\end{array}$ & AST (U/I) & $\operatorname{ALT}(\mathbf{U} / \mathbf{l})$ & $\begin{array}{c}\text { Total protein } \\
\text { (g/dI) }\end{array}$ \\
\hline Group 1 & $22.06 \pm 1.08^{\mathrm{h}}$ & $0.41 \pm 0.20^{\mathrm{d}}$ & $0.60 \pm 0.02^{\mathrm{d}}$ & $119.81 \pm 2.82^{\mathrm{d}}$ & $75.87 \pm 3.11^{\mathrm{d}}$ & $3.86 \pm 0.13^{\mathrm{a}}$ \\
\hline Group 2 & $63.81 \pm 0.85^{\mathrm{e}}$ & $0.73 \pm 0.017^{\mathrm{c}}$ & $0.79 \pm 0.03^{\mathrm{d}}$ & $314.87 \pm 22.69^{b}$ & $85.03 \pm 2.33^{c}$ & $2.66 \pm 0.08^{\mathrm{bc}}$ \\
\hline Group 3 & $61.12 \pm 0.2^{\mathrm{g}}$ & $0.55 \pm 0.04^{\mathrm{d}}$ & $0.69 \pm 0.01^{\mathrm{d}}$ & $248.34 \pm 19.41^{\mathrm{c}}$ & $78.27 \pm 1.29^{\mathrm{d}}$ & $2.90 \pm 0.12^{\mathrm{b}}$ \\
\hline Group 4 & $71.70 \pm 0.25^{\mathrm{c}}$ & $0.83 \pm 0.01^{\mathrm{c}}$ & $1.13 \pm 0.04^{\mathrm{c}}$ & $395.43 \pm 22.53^{\mathrm{a}}$ & $91.25 \pm 1.94^{\mathrm{bc}}$ & $2.32 \pm .25^{\mathrm{cd}}$ \\
\hline Group 5 & $68.85 \pm 0.69^{b}$ & $0.72 \pm 0.02^{\mathrm{c}}$ & $1.22 \pm .19 \mathrm{~b}^{\mathrm{c}}$ & $267.28 \pm 15.25^{\mathrm{bc}}$ & $86.50 \pm 1.83^{c}$ & $2.34 \pm 0.13^{\mathrm{cd}}$ \\
\hline Group 6 & $78.80 \pm 1.01^{\mathrm{a}}$ & $1.42 \pm 0.10^{\mathrm{a}}$ & $1.92 \pm 0.13^{\mathrm{a}}$ & $390.36 \pm 20.66^{\mathrm{a}}$ & $103.39 \pm 2.18^{\mathrm{a}}$ & $1.96 \pm 0.08^{\mathrm{d}}$ \\
\hline Group 7 & $75.00 \pm 0.51^{\mathrm{b}}$ & $1.07 \pm 0.07^{\mathrm{b}}$ & $1.43 \pm 0.03^{\mathrm{b}}$ & $306.76 \pm 24.66^{\mathrm{bc}}$ & $94.98 \pm 2.19^{\mathrm{b}}$ & $2.32 \pm 0.14^{\mathrm{cd}}$ \\
\hline
\end{tabular}

Means label different superscripts $\left({ }^{\text {abcd }}\right)$ letters at the same column are significantly different at $\mathrm{P}<0.05$. BUN: blood urea nitrogen, AST: Aspartate aminotransferase, ALT: Alanine aminotransferase group1 is negative control, groups 2, 4, and 6 received melamine at dose of $0.9,90$ and 9000 ppm respectively while groups $3,5,7$ received melamine in dose of $0.9,90$ and $9000 \mathrm{ppm}$ beside $2.5 \mathrm{gm} / \mathrm{kg} \mathrm{B.W}$.

Table 4. Electrolytes changes among different melamine doses and honey treated male rat's groups

\begin{tabular}{lccccc}
\hline Groups & $\begin{array}{c}\text { Ca mg/dl } \\
(\text { Mean } \pm \text { SE) }\end{array}$ & $\begin{array}{c}\text { Phos mg/dl } \\
(\text { Mean } \pm \text { SE) }\end{array}$ & $\begin{array}{c}\text { Na mgEq/I } \\
(\text { Mean } \pm \text { SE) }\end{array}$ & $\begin{array}{c}\text { K mgEq/I } \\
(\text { Mean } \pm \text { SE) }\end{array}$ & $\begin{array}{c}\text { Cl mgEq/I } \\
(\mathbf{M e a n} \pm \text { SE) }\end{array}$ \\
\hline Group 1 & $9.36 \pm 0.31^{\mathrm{a}}$ & $9.70 \pm 0.21^{\mathrm{a}}$ & $147.00 \pm 1.00^{\mathrm{a}}$ & $6.82 \pm 0.10^{\mathrm{a}}$ & $107.60 \pm 0.87^{\mathrm{a}}$ \\
Group 2 & $3.36 \pm 0.08^{\mathrm{c}}$ & $6.20 \pm 0.27^{\mathrm{d}}$ & $135.20 \pm 1.53^{\mathrm{b}}$ & $5.86 \pm 0.11^{\mathrm{c}}$ & $98.20 \pm 1.36^{\mathrm{bc}}$ \\
Group 3 & $6.51 \pm 0.61^{\mathrm{b}}$ & $8.14 \pm 0.12^{\mathrm{b}}$ & $136.40 \pm 1.03^{\mathrm{b}}$ & $6.74 \pm 0.47^{\mathrm{ab}}$ & $101.00 \pm 1.52^{\mathrm{b}}$ \\
Group 4 & $1.49 \pm 0.09^{\mathrm{e}}$ & $6.76 \pm 0.21^{\mathrm{c}}$ & $121.20 \pm 2.80^{\mathrm{c}}$ & $4.68 \pm 0.43^{\mathrm{de}}$ & $93.60 \pm 1.08^{\mathrm{c}}$ \\
Group 5 & $3.14 \pm 0.05^{\mathrm{cd}}$ & $5.06 \pm 0.12^{\mathrm{e}}$ & $131.80 \pm 1.07^{\mathrm{b}}$ & $5.94 \pm 0.27^{\mathrm{bc}}$ & $85.40 \pm 3.59^{\mathrm{d}}$ \\
Group 6 & $1.44 \pm 0.04^{\mathrm{e}}$ & $3.84 \pm 0.11^{\mathrm{g}}$ & $89.20 \pm 2.15^{\mathrm{e}}$ & $4.20 \pm 0.26^{\mathrm{e}}$ & $84.40 \pm 1.29^{\mathrm{d}}$ \\
Group 7 & $2.47 \pm 0.10^{\mathrm{d}}$ & $4.52 \pm 0.17^{\mathrm{f}}$ & $107.40 \pm 2.94^{\mathrm{d}}$ & $5.38 \pm 0.12^{\mathrm{cd}}$ & $65.80 \pm 1.98^{\mathrm{e}}$ \\
\hline
\end{tabular}

Means label different superscripts ( ${ }^{\text {abcd....) }}$ letters at the same column are significantly different at $\mathrm{P}<0.05$. Ca: calcium, phos: phosphorus, Na: sodium, K: potassium, CL: chlorine Group1 is negative control, groups 2, 4, and 6 received melamine at dose of $0.9,90$ and 9000 ppm respectively while groups $3,5,7$ received melamine in dose of $0.9,90$ and $9000 \mathrm{ppm}$ beside $2.5 \mathrm{gm} / \mathrm{kg} \mathrm{B.W}$.

Moreover, blood capillaries presented mild congestion in submucosa and lamina propria. On the other side, fused intestinal villi with necrosis of their lining epithelial cells were noticed in rats obtained from G4 and G6. Additionally, desquamation of the necrosed villar epithelium with mononuclear cells infiltration into the lamina propria (Figures $2 \mathrm{f}$ and $2 \mathrm{~g}$ ) with mild hemorrhage was seen in other cases. Edema and necrosis of the muscularis mucosae was demonstrated in some rats of G6. In addition to some lymphocytic infiltration in sub-mucosa, necrosis of the epithelial cells lining the intestinal glands with sever infiltration of mononuclear inflammatory cells and increase in the goblet cells of the intestinal villi was observed as well as infiltration of inflammatory cells in between the intestinal glands. Vacuolation of the glandular epithelium with its engorgement with lymphocytes was also seen among group 6. Remarkably, the microscopical examination of different organs obtained from rats treated with different concentrations of melamine $(0.9$, 90 and $9000 \mathrm{ppm}$ ) and honey treated animals (G3, G5 and G7) for 45 days revealed marked ameliorative effect of honey with variable degrees to the histopathological alterations induced by melamine in different investigated organs especially in rats of G3. Accordingly, improvement in the hepatocellular architecture with more regular and less altered hepatocytes except dilatation of central vein (Figure $2 \mathrm{~h}$ ) when compared to melamine treated rats only was demonstrated. In contrast, the hepatic tissues obtained from rats of G5 revealed mild reduction in the severity of pathological changes induced by melamine as congested central veins and mild sinusoidal dilatation with a mild degree of degenerative changes in hepatocytes with mild perivascular edema (Figure 2i) However, hydropic degeneration of hepatocytes with small area of coagulative necrosis was detected in the hepatic parenchyma of only two animals. Meanwhile, treatment of melamineintoxicated rats with honey (G7) resulted in a mild improvement in the lesions induced by melamine, but it still having some pathological alterations, as the liver showed numerous swollen hepatocytes with vacuolar degeneration in combination with focal areas of hemorrhage in hepatic parenchyma. Focal areas of coagulative necrosis were detected in two examined cases. Slight hyperplasia of the biliary epithelium and activation of Von Kupffer cell (Figure 2j) in comparable to those of the control group. Kidneys of G3 showed nearly normal histological structure in most rats except mild degeneration of the lining epithelium of renal tubules with vacuolation of the endothelial cell lining of glomerular tuft (Figure 2k). Meanwhile, the renal tissue obtained from G5 revealed tubular changes, some tubules showed disintegration of the glomerular tuft with lining epithelium degenerative changes. Moreover, cellular and hyaline casts (Figure 2L) was also noticed in the lumen of some renal tubules. Furthermore, few leukocytic infiltration mainly macrophage and lymphocytes as well as necrosis of the lining epithelium with cellular and hyaline cast was observed. Degenerative changes in the endothelial cell lining of the glomerular tuft (Figure 2m) was seen in the renal tissues of G7. Hyperplasia of the glomerular tuft with reduction in Bowman's space was also observed in few animals among this group. Microscopically, the most common pathological changes detected in the pulmonary tissues obtained from groups G3, G5 and G7 were emphysema in which pulmonary alveoli were enlarged with few consolidated alveoli (Figures $2 \mathrm{n}$ 
and 2o). Interestingly, cardiac tissues appeared normal in most examined cases of G3 (Figure 2p). Mild degenerative changes in the sarcoplasm of cardiac muscle were common pathological changes (Figure 2q) seen in the heart of G5. On the other side, congestion of myocardial blood vessels with degeneration in the wall of myocardial blood vessels in combination with mild hyaline degeneration of the cardiac muscles (Figure 2r) was observed in some rats mainly from G7. Intestine showed mild degeneration of the lining epithelium of intestinal villi with hyperplasia of goblet cells was noticed in intestine from G3. Meanwhile, less necrotic changes with few inflammatory cells in the lumen of the villi and in lamina propria of intestine of rats from G5 and G7 (Figure 2s).

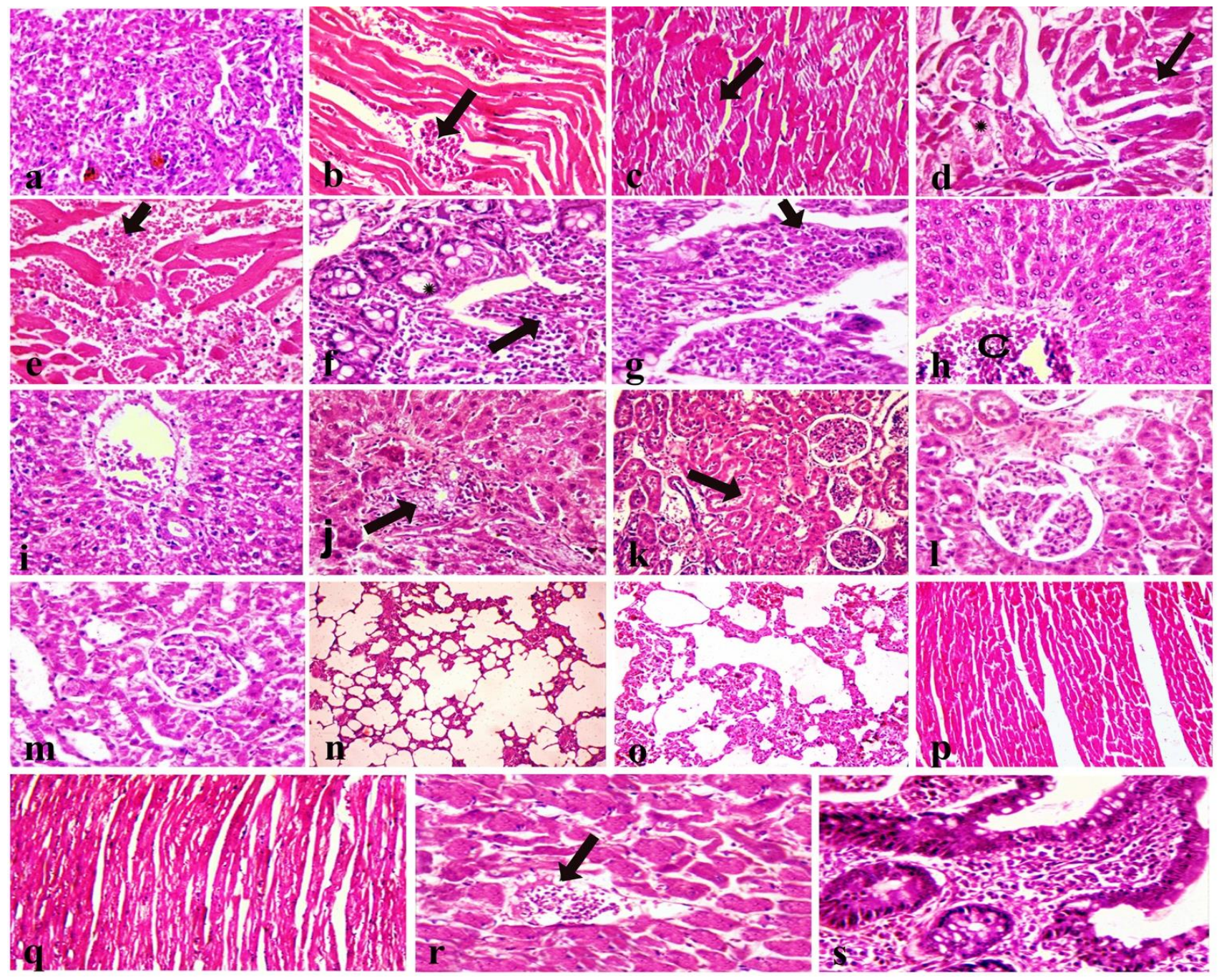

Figure 2. Histological changes among different organs of male rats treated with different melamine concentration and bee's honey, Pulmonary changes among melamine treated groups, H \& E stained section of lung obtained from group 6 (a) showing Extensive diffuse consolidation of pulmonary alveoli (x 200). Cardiac changes among melamine treated groups (b, c, $\mathbf{d}$ and e). H\&E stained section of heart, group 2 (b and c), group 4 (d), group 6 (e), b: showing Intermuscular hemorrhage (arrow, x200), c: Hyaline degeneration of some cardiac muscles (arrow, x 200), d: Clear vacuolation of the sarcoplasm of cardiac muscles (arrow) with myomalacia of some muscle fiber (asterisk, x 200), e: Marked intermuscular hemorrhage admixed with few leukocytic infiltration (arrow) with hyaline degeneration of the cardiac muscles (x 200), Intestinal changes of melamine treated groups (f and $\mathbf{g}$ ) (H\&E stained section), f: Mononuclear leukocytic cellular infiltrations in the lamina propria of intestinal villi (arrow) with vacuolation and necrosis of the lining epithelium of sub-mucosal gland (asterisk, x 400), g: Entire necrosis of the lining epithelium of intestinal villi (arrow) with leukocytic cellular infiltrations in the lamina propria (x 400). Liver and kidney histological changes, H\&E stained section obtained from liver, group $3(\mathbf{h})$, group $5(\mathbf{i})$, group7 $(\mathbf{j})$, h: showing normal histological structure of hepatic tissue except dilatation of central vein (C, x 200), i: Congestion of portal blood vessels with mild perivascular edema with mild vacuolar degeneration of hepatocytes (x 200), j: Mild proliferation of the lining epithelium of bile duct (arrow) with mild vacuolar degeneration of hepatocytes (x 200). While kidney's, $\operatorname{group}_{3}(\mathbf{k})$, group $5(\mathbf{l}), \operatorname{group}_{7}(\mathbf{m}), \mathbf{k}$ : Clear vacuolation of the endothelial cell lining of glomeruli with the presence of eosinophilic hyaline casts in the lumen of some renal tubules (arrow, x 100), l: Disintegration of the glomerular tuft with the presence of cellular casts in the lumen of some renal tubules (arrow, x 200), m: Degenerative changes in the endothelial cell lining of the glomerular tuft with necrosis of the lining epithelium of some renal tubules (x 200). Histological changes, H\&E stained section of lung (n and o), n: obtained from group3 showing emphysema in the pulmonary tissue (x 200), o: obtained from group7 showing compensatory emphysema with few consolidated alveoli (x 200), p: obtained from group3 showing normal histological structure of cardiac muscle (x 200), q: obtained from group5 showing mild degenerative changes in the sarcoplasm of cardiac muscle (x 200), $\mathbf{r}$ : obtained from group7 showing hyaline degeneration in some cardiac muscle fiber with vacuolar degeneration in the wall of myocardial blood vessels (x 200), s: obtained from group7 showing mild degenerative changes in the lining epithelium of the intestinal villi with few mononuclear leukocytic cellular infiltration in the lamina propria (x 400). 
Falsely, melamine could be used to increase the feedstuffs nitrogen concentration. Mammalian bodies can't metabolize melamine (Jutzi et al., 1982; Hammond et al., 1986), so once it is ingested it results in insoluble crystals that obstruct and damage renal tubules and leads to renal failure (Brown et al., 2007; Puschner et al., 2007). World Health Organization (WHO) stated that the human tolerable daily melamine dose is $0.2 \mathrm{mg}$ per kilogram of body weight whereas, the Food and Drug Administration (FDA) recommended dose is 2.5 part per million in food and one part per million for infant formula (Ingelfinger, 2008). Melamine contaminated milk products results in infants and children urinary system calculi (Ingelfinger, 2008; Lam et al., 2008; Xin and Stone, 2008). Above recommended dose, toxicity and renal calculus formation increase with melamine dose increase (Lam et al., 2008). Attempts have been made to select ameliorative agents to reduce obvious melamine toxicity to the exposed individuals. Bee's honey is known to have a wide antioxidant and protective properties range (Al-Hindi et al., 2011). The histopathological changes in the most of examined vital assets (liver, kidney, heart, intestine and lungs) was melamine concentrations dependent, as the severity of the alterations was increased by increasing the concentration of melamine. These results controversy with those of Shehu et al. (2015) who showed no histopathological changes in melamine treated male albino rats at 28 days, this may be because of the variation in exposure period of melamine toxicity. However, the bee's honey treated animals revealed some pathological changes than the only melamine treated animals and this finding matched with the result of Wilson et al. (2011) who ascribed the protective rule of bee's honey on liver of adult Wister rats. In present study, convulsions and nervous manifestation have been recorded in some animals before death, these finding agreed with Zhang et al. (2009), they attributed similar findings to the toxic effect of melamine on brain tissue and azotemia. Besides An et al. (2012) showed that the melamine could pass the blood brain barrier and affected potassium and sodium channel in hippocampal neurons causes synaptic plasticity impairments. Regarding the postmortem (PM) changes, urinary bladder and ureters showed distention with white crystals that might be ascribe to melamine crystals deposition on the urinary system. This observation was consistent with Xin and Stone (2008). Available suggestion about susceptibility of hepatocytes to damage during oxidative stress and the proven antioxidants beneficial effect was reported by Dias et al. (2005) and Gumieniczek (2005). In the current study significant increases in the oxidative stress marker Glutathione (GSH), Malondialdehyde (MDH) and catalase) in all melamine treated animals was obtained compared to control animals, this result disagree with the finding of Kilicoglu et al. (2008) and Lv et al. (2013), who showed marked reduction in the oxidative stress markers after melamine administration for 13 weeks in mice, this controversy may be due to the longer period that is enough to deplete cellular antioxidant reserve. Bee's honey treated rats caused marked reduction in antioxidant markers (GSH, MDH) compared to corresponding groups that received melamine only, this finding matched with report of Yao et al. (2011), who proved that the bee's honey effectively restored the antioxidant (GSH, MDH) reserve in male rat's hepatocytes and Al-Waili (2003) who proved the bee's honey had valuable antioxidant effect on sheep. Although the antioxidant effect of bee's honey on catalase level in the hepatocytes was moderate this finding was according to with report of Petrus et al. (2011) who indicated moderate effect of bee's honey on catalase enzyme concentration in hepatocytes. It is truly reported that the oxidative stress and inflammation are correlated (Peake et al., 2007). Bee's honey possessed both antioxidant and anti-inflammatory, so this fact makes the ameliorative effect of bee's honey to be more pronounced (Kassim et al., 2010; Omotayo et al., 2010; Erejuwa et al., 2011). Blood is considered as sensitive and good index of any physiological changes, so any toxic stress would show great hematological parameters changes. This study showed a significant decrease in RBCs, HB\%, and PCV\% in the melamine treated groups (for 45 days) than control group, this may be due to the cytotoxic effect of melamine on different body organs, this observation is in concordant with Zhang et al. (2009). Reduction in these parameters may be up to produced enteritis that caused thickening and shortening in the intestinal villi with fibrous tissue formation in mucosa and submucosa (Bhor and Sivakami, 2003; Weiss and Wardrop, 2011), these changes resulted in nutrients poor absorption. Strakova et al. (2014) reported that the reduction in RBCs counts mainly is due to the negative impact of melamine toxicity on the RBCs life span through increasing their membrane fragility via decreasing Na+/K- ATPase activity. The melamine induced nephrotoxicity may have negative effect in the erythropoietin hormone production as stated by Hau et al. (2009); Doubek et al. (2010). Many authors (Zheng et al., 2013) referred the reduction on RBCs, HB\% and PCV\% to suppressor effect of melamine toxicity on bone marrow multiplication. The bee's' honey treated animal groups obtained significant increases in the RBCs, HB\% and PCV\%. Yao et al. (2011) stated this increase is due to the marked antioxidant and protective rule of bee's' honey that restore the activity of catalase and glutathione peroxidase. Some researchers (Yao et al., 2004; Michalkiewicz et al., 2008) attributed the hematological parameters increases to the antioxidant's properties of honey as well as its high contents of moisture, sugars such as fructose, glucose, enzymes like glutathione reductase and catalase, in addition to essential elements such as iron, copper, zinc, and calcium, vitamins such as vitamin A, C, and E, and some flavonoids and phenolic acids. This study indicated significant decrease the total leukocyte counts this finding is concordant with Strakova et al. (2014), this might be due to the undesirable effect of melamine on the cell membrane integrity. Some authors (El Rabey et al., 2013) correlated the reduction in the leukocyte counts to the hepatoxicity and 
decreased the liver activities. Meanwhile the bee's honey treated groups revealed significant increase in the leukocyte count which might be due to the antioxidant effect of the bee's honey, this finding was agreed with Al-Waili (2003) who reported similar finding in human. Concerning the biochemical evaluation, the result obtained in this study showed marked elevation in the BUN, creatinine, and uric acid in melamine treated rats' group, this finding concordant with the finding of Jingbin et al. (2010). Dogs and cats presented alike results (Cianciolo et al., 2008; Dobson et al., 2008). This elevation in the urea, uric acid and creatinine may be attributed to renal ischemia and focal lesion produced due to melamine toxicity, this hypothesis agrees with Ogasawara et al. (1995), who has found similar results on rats. Bee's honey fed groups indicated significant reduction in the serum level of urea, uric acid and creatinine. These findings matched with those proved by Erejuwa et al. (2012) who stated that bee's honey has marked antioxidant and protective effect on the kidney. Regarding to liver assessing serum parameters (AST, ALT, and total protein), significant increase in the serum level of AST and ALT have been recorded in this study, this may be due to the oxidative stress produced through the melamine toxic effect of the liver cells that resulting in increased the lysis of hepatocyte and release of its enzymes (AST and ALT). This finding agrees with Khan et al. (2005), in this respect Hayes et al. (1999) stated that increased serum level of AST and ALT indicate pronounced liver cell damages. However, this finding is disagreed with Puschner and Reimschuessel (2011) who showed decrease in the AST and ALT in dogs and cats exposed to melamine toxicity. The bee's honey treated animals (at $2.5 \mathrm{gm} / \mathrm{kg}$ lbody weight) showed marked reduction in the liver enzyme (AST and ALT) this could be due to the antioxidant effect of bee's honey on the hepatic cells, this result concurred with Erejuwa et al. (2012). It is true that most of plasma protein synthesis occurs in liver, so total plasma protein can be use as indicator about the liver cell function (Yang and Chen, 2003). The study presented marked reduction in total serum protein in the melamine treated rats, which may be caused by hepatotoxicity, this result matched with those ascribed with Chen et al. (2009) who stated that the melamine toxicity results in nephritis, and may lead to increase the filtration and loss of albumen in urine. Whenever the bee's honey treated animals showed marked increase in serum total protein, this result may be due to the bee's honey ameliorative effect on liver cells, and concordant with findings of El-Khayat and Ahmed (2000).

The current study showed a significant reduction in electrolytes $(\mathrm{Ca}, \mathrm{ph}, \mathrm{Na}, \mathrm{K}$, and $\mathrm{Cl})$. Serum, these findings concordant with the declaration of Abdel-Gayoum and Ahmida (2017) who presented noticeable decrease in serum electrolytes, and ascribed this finding to the nephrotoxicity that hindered the tubular reabsorption of these electrolytes and increased their renal excretions. Bee's honey treated groups showed marked elevation in the serum level of these electrolytes ( $\mathrm{Ca}, \mathrm{ph}, \mathrm{Na}, \mathrm{K}$, and $\mathrm{Cl}$ ), which may be due to the proven antioxidant effect that caused decrease in melamine nephrotoxic effect. These findings are in line with report of Wilson et al. (2011) who stated that, the protective effect of bee's' honey could be attributed to their biologically active compounds such as vitamins, flavonoids, and antioxidants that synergistically work to clean the oxidative stress produced free radicals.

\section{CONCLUSION}

The current study, disclosed the protective effect of bee's' honey against melamine induced toxicity. This fact was concluded from its ameliorative effect in biochemical, hematological and tissue histopathological alterations induced by different concentrations of melamine. Thus, bee's' honey might be used to protect

\section{DECLARATIONS}

\section{Author's contribution}

Ahlam F. Hamouda and Samar S have designed and performed experimental work. Aziza Amin has performed the histopathological changes. Mohamed A Mahmoud has performed the serum analysis, statistical analysis, writing and publication.

\section{Consent to publish}

The authors allow the publisher the only and sole license of the patent in the contribution. So, the publisher shall have the special right throughout the world to publish and sell the contribution in all languages and all other forms of electronic publication.

\section{Competing interests}

All authors have no conflict of interest.

\section{REFERENCES}

Abdul-Ghani A-S, Dabdoub N, Muhammad R, Abdul-Ghani R and Qazzaz M (2008). Effect of palestinian honey on spermatogenesis in rats. Journal of medicinal food, 11 (4): 799-802. Doi: 10.1089/jmf.2008.0085

Abdel-Gayoum AA and Ahmida MHS (2017). Changes in the serum, liver, and renal cortical lipids and electrolytes in rabbits with cisplatin-induced nephrotoxicity. Turkish journal of medical sciences, 47 (3): 1019-1027. Doi: 10.3906/sag-1602-136 
Al-Hindi RR, Bin-Masalam MS and El-Shahawi MS (2011). Antioxidant and antibacterial characteristics of phenolic extracts of locally produced honey in saudi arabia. International journal of food sciences and nutrition, 62 (5): 513-517. Doi: $10.3109 / 09637486.2010 .550276$

Al-Waili NS (2003a). Effects of daily consumption of honey solution on hematological indices and blood levels of minerals and enzymes in normal individuals. Journal of medicinal food, 6 (2): 135-140. Doi:10.1089/109662003322233549

Al-Waili NS (2003b). Intravenous and intrapulmonary administration of honey solution to healthy sheep: Effects on blood sugar, renal and liver function tests, bone marrow function, lipid profile, and carbon tetrachloride-induced liver injury. Journal of medicinal food, 6 (3): 231-247. Doi:10.1089/10966200360716652

An L, Li Z, Yang Z and Zhang T (2011). Cognitive deficits induced by melamine in rats. Toxicology letters, 206 (3): $276-280$. Doi: 10.1016/j.toxlet.2011.08.009

An L, Li Z, Yang Z and Zhang T (2012). Melamine induced cognitive impairment associated with oxidative damage in rat's hippocampus. Pharmacology Biochemistry and Behavior, 102 (2): 196-202. Doi: 10.1016/j.pbb.2012.04.009

Beutler E (1963). Improved method for determination of blood glutathione. Journal of Laboratory and Clinical Medicine, 61 (5): $882-$ 888.

Bhalla V, Grimm PC, Chertow GM and Pao AC (2009). Melamine nephrotoxicity: An emerging epidemic in an era of globalization. Kidney international, 75 (8): 774-779. Doi: 10.1038/ki.2009.16

Bhor VM and Sivakami S (2003). Regional variations in intestinal brush border membrane fluidity and function during diabetes and the role of oxidative stress and non-enzymatic glycation. Molecular and Cellular Biochemistry, 252 (1-2): 125-132. Doi: 10.1023/a:1025599126840

Blasa M, Candiracci M, Accorsi A, Piacentini MP, Albertini MC and Piatti E (2006). Raw millefiori honey is packed full of antioxidants. Food Chemistry, 97 (2): 217-222. Doi: 10.1016/j.foodchem.2005.03.039

Brown CA, Jeong K-S, Poppenga RH, Puschner B, Miller DM, Ellis AE, Kang K-I, Sum S, Cistola AM and Brown SA (2007). Outbreaks of renal failure associated with melamine and cyanuric acid in dogs and cats in 2004 and 2007. Journal of Veterinary Diagnostic Investigation, 19 (5): 525-531.Doi: 10.1177/104063870701900510

Chan EYY, Griffiths SM and Chan CW (2008). Public-health risks of melamine in milk products. The Lancet, 372 (9648): 1444-1445. Doi: 10.1016/S0140-6736(08)61604-9

Chen K-C, Liao C-W, Cheng F-P, Chou C-C, Chang S-C, Wu J-H, Zen J-M, Chen Y-T and Liao J-W (2009). Evaluation of subchronic toxicity of pet food contaminated with melamine and cyanuric acid in rats. Toxicologic pathology, 37 (7): $959-968$. Doi: $10.1177 / 0192623309347910$

Cianciolo RE, Bischoff K, Ebel JG, Van Winkle TJ, Goldstein RE and Serfilippi LM (2008). Clinicopathologic, histologic, and toxicologic findings in 70 cats inadvertently exposed to pet food contaminated with melamine and cyanuric acid. Journal of the American Veterinary Medical Association, 233 (5): 729-737. Doi: 10.2460/javma.233.5.729

Dias AS, Porawski M, Alonso M, Marroni N, Collado PS and Gonzalez-Gallego J (2005). Quercetin decreases oxidative stress, nf-kb activation, and inos overexpression in liver of streptozotocin-induced diabetic rats. The Journal of nutrition, 135 (10): 2299 2304. https://doi.org/10.1093/jn/135.10.2299

Dobson RLM, Motlagh S, Quijano M, Cambron RT, Baker TR, Pullen AM, Regg BT, Bigalow-Kern AS, Vennard T, Fix A, et al. (2008). Identification and characterization of toxicity of contaminants in pet food leading to an outbreak of renal toxicity in cats and dogs. Toxicological Sciences, 106 (1): 251-262. https://doi.org/10.1093/toxsci/kfn160

Doubek J, Slosarkova S, Rehakova K, Bouda J, Scheer P, Piperisova I, Tomenendalova J and Matalova E (2010). The interpretation of basic biochemical and haematological indices in animals. Noviko, Czech Republic (in Czech), p. 102.

El-Khayat Z and Ahmed HH (2000). Antitumer efficacy of edible portulaca oleracea and bee's honey in mice inoculated with ehrlich ascttes tumer cells. Journal of Union of Arab Biologists, 13: 583-605. Doi:10.1007/springerreference_69205

El Rabey HA, Al-Seeni MN and Al-Solamy SM (2013). Bee's' honey protects the liver of male rats against melamine toxicity. BioMed research international, 2013: 1-8. Doi: 10.1155/2013/786051

Erejuwa OO, Sulaiman SA and Ab Wahab MS (2012). Honey: A novel antioxidant. Molecules, 17 (4): 4400-4423. Doi: 10.3390/molecules 17044400

Erejuwa OO, Sulaiman SA, Wahab MS, Sirajudeen KNS, Salleh SM and Gurtu S (2011). Effect of glibenclamide alone versus glibenclamide and honey on oxidative stress in pancreas of streptozotocin-induced diabetic rats. International Journal of Applied Research in Natural Products, 4 (2): 1-10. Doi: 10.3390/ijms11052056

Filigenzi MS, Puschner B, Aston LS and Poppenga RH (2008). Diagnostic determination of melamine and related compounds in kidney tissue by liquid chromatography/tandem mass spectrometry. Journal of Agricultural and Food Chemistry, 56 (17): 7593 7599. Doi: $10.1021 / \mathrm{jf} 801008 \mathrm{~s}$

Grindem CB (2011). Schalm's veterinary hematology, 6th edition. Editors: Douglas j. Weiss, k. Jane wardrop. Veterinary Clinical Pathology, 40 (2): 270-270. Doi:10.1111/j.1939-165x.2011.00324.x

Gumieniczek A (2005). Oxidative stress in kidney and liver of alloxan-induced diabetic rabbits: Effect of repaglinide. Acta diabetologica, 42 (2): 75-81. Doi: 0.1007/s00592-005-0182-2

Hadwan MH (2016). New method for assessment of serum catalase activity. Indian Journal of Science and Technology, 9 (4). Doi: 10.17485/ijst/2016/v9i4/80499

Hammond BG, Barbee SJ, Inoue T, Ishida N, Levinskas GJ, Stevens MW, Wheeler AG and Cascieri T (1986). A review of toxicology studies on cyanurate and its chlorinated derivatives. Environmental Health Perspectives, 69: 287. Doi: 10.1289/ehp.8669287 
Hau AK-c, Kwan TH and Li PK-t (2009). Melamine toxicity and the kidney. Journal of the American Society of Nephrology, 20 (2): 245-250. Doi: 10.1681/asn.2008101065

Hayes JM, Strauss H and Kaufman AJ (1999). The abundance of 13c in marine organic matter and isotopic fractionation in the global biogeochemical cycle of carbon during the past 800 ma. Chemical Geology, 161 (1-3): 103-125. Doi: 10.1016/s00092541(99)00083-2

Henry RJ (1974). Determination of serum creatinine. Clinical Chemistry: Principles and Techniques. second edition. Harper and Row Publishers, New York, pp. 104-106

Ingelfinger JR (2008). Melamine and the global implications of food contamination. New England Journal of Medicine, 359 (26): 2745-2748. Doi: 10.1056/nejmp0808410

Jingbin W, Ndong M, Kai H, Matsuno K and Kayama F (2010). Placental transfer of melamine and its effects on rat dams and fetuses. Food and Chemical Toxicology, 48 (7): 1791-1795. Doi: 10.1016/j.fct.2010.03.043

Johnston JE, Sepe HA, Miano CL, Brannan RG and Alderton AL (2005). Honey inhibits lipid oxidation in ready-to-eat ground beef patties. Meat science, 70 (4): 627-631. Doi: 10.1016/j.meatsci.2005.02.011

Jutzi K, Cook AM and Hütter R (1982). The degradative pathway of the s-triazine melamine. The steps to ring cleavage. Biochemical Journal, 208 (3): 679-684. Doi: 10.1042/bj2080679

Kassim M, Achoui M, Mansor M and Yusoff KM (2010). The inhibitory effects of gelam honey and its extracts on nitric oxide and prostaglandin e2 in inflammatory tissues. Fitoterapia, 81 (8): 1196-1201. Doi: 10.1016/j.fitote.2010.07.024

Khan SM, Sobti RC and Kataria L (2005). Pesticide-induced alteration in mice hepato-oxidative status and protective effects of black tea extract. Clinica Chimica Acta, 358 (1-2): 131-138. Doi: 10.1016/j.cccn.2005.02.015

Khan SR (2006). Renal tubular damage/dysfunction: Key to the formation of kidney stones. Urological research, 34 (2): 86-91. Doi: $10.1007 / \mathrm{s} 00240-005-0016-2$

Kilicoglu B, Gencay C, Kismet K, Kilicoglu SS, Erguder I, Erel S, Sunay AE, Erdemli E, Durak I and Akkus MA (2008). The ultrastructural research of liver in experimental obstructive jaundice and effect of honey. The American Journal of Surgery, 195 (2): 249-256. Doi: 10.1016/j.amjsurg.2007.04.011

Kochmar J and Mossa D (1976). Foundamental of clinical chemistry. first edition. Philadelphia: W.B. Saunders Company, p. 606.

Lam HS, Ng PC, Chu WCW, Wong W, Chan DFY, Ho SS, Wong KT, Ahuja AT and Li CK (2008). Renal screening in children after exposure to low dose melamine in hong kong: Cross sectional study. British Medical Journal, 337: 2991. Doi: 10.1136/bmj.a2991

Leary NO, Pembroke A and Duggan PF (1992). Single stable reagent (arsenazo iii) for optically robust measurement of calcium in serum and plasma. Clinical Chemistry, 38 (6): 904-908. Doi: 10.1177/000456329202900113

Li L, Li B, Cheng D and Mao L (2010). Visual detection of melamine in raw milk using gold nanoparticles as colorimetric probe. Food Chemistry, 122 (3): 895-900.

Lustgarten JA, Wenk RE, Byrd C and Hall B (1974). Evaluation of an automated selective-ion electrolyte analyzer for measuring na+, k+, and cl-in serum Clinical Chemistry, 20 (9): 1217-1221. Doi: 10.1093/ajcp/59.4.542

Lv Y, Liu P, Xiang C and Yang H (2013). Oxidative stress and hypoxia observed in the kidneys of mice after a 13-week oral administration of melamine and cyanuric acid combination. Research in Veterinary Science, 95 (3): 1100-1106. Doi: 10.1016/j.rvsc.2013.10.001

Michalkiewicz A, Biesaga M and Pyrzynska K (2008). Solid-phase extraction procedure for determination of phenolic acids and some flavonols in honey. Journal of chromatography A, 1187 (1-2): 18-24. Doi: 10.1016/j.chroma.2008.02.001

Morris JL and Macleod AG (1922). Colorimetric determination of uric acid: Estimation of 0.03 to $0.5 \mathrm{mg}$. Quantities by a new method Journal of Biological Chemistry, 50: 55. Doi: 10.1021/ac60058a044

Munoz MA, Balon M and Fernandez C (1983). Direct determination of inorganic phosphorus in serum with a single reagent. Clinical Chemistry, 29 (2): 372-374. Doi: 10.1039/an9790401124

Ogasawara H, Imaida K, Ishiwata H, Toyoda K, Kawanishi T, Uneyama C, Hayashi S, Takahashi M and Hayashi Y (1995). Urinary bladder carcinogenesis induced by melamine in 344 male rats: Correlation between carcinogenicity and urolith formation. Carcinogenesis, 16 (11): 2773-2777. Doi: 10.1093/carcin/16.11.2773

Ohkawa H, Ohishi N and Yagi K (1979). Assay for lipid peroxides in animal tissues by thiobarbituric acid reaction. Analytical Biochemistry, 95 (2): 351-358. Doi: 10.1016/0003-2697(79)90738-3

Omotayo EO, Gurtu S, Sulaiman SA, Wahab MSA, Sirajudeen KNS and Salleh MSM (2010). Hypoglycemic and antioxidant effects of honey supplementation in streptozotocin-induced diabetic rats. International Journal for Vitamin and Nutrition Research, 80 (1): 74. Doi: 10.1024/0300-9831/a000008

Patton GJ and Crouch SR (1977). Determination of urea (urease modified berthelot reaction). Analytical Chemistry, 49: 464-469. Doi: 10.1021/ac50011a034

Peake JM, Suzuki K and Coombes JS (2007). The influence of antioxidant supplementation on markers of inflammation and the relationship to oxidative stress after exercise. The Journal of Nutritional Biochemistry, 18 (6): 357-371. Doi: 10.1016/j.jnutbio.2006.10.005

Petrus K, Schwartz H and Sontag G (2011). Analysis of flavonoids in honey by hplc coupled with coulometric electrode array detection and electrospray ionization mass spectrometry. Analytical and bioanalytical chemistry, 400 (8): 2555-2563. Doi: 10.1007/s00216-010-4614-7

Puschner B, Poppenga RH, Lowenstine LJ, Filigenzi MS and Pesavento PA (2007). Assessment of melamine and cyanuric acid toxicity in cats. Journal of Veterinary Diagnostic Investigation, 19 (6): 616-624. Doi: 10.1177/104063870701900602 
Puschner B and Reimschuessel R (2011). Toxicosis caused by melamine and cyanuric acid in dogs and cats: Uncovering the mystery and subsequent global implications. Clinics in laboratory medicine, 31 (1): 181-199. Doi: 10.1016/j.cll.2010.10.003

Reitman S and Frankel S (1957). A colorimetric method for the determination of serum glutamic oxalacetic and glutamic pyruvic transaminases. American journal of clinical pathology, 28 (1): 56-63. Doi: 10.1093/ajcp/28.1.56

Shehu S, Wasagu RSU, Lawal M and Albert AK (2015). Effect of melamine adulteration on body weight, liver and kidney histology and liver function indices of albino rats. Asian Journal of Biochemistry, 10 (3): 125-131. Doi: 10.3923/ajb.2015.125.131

Stine CB, Reimschuessel R, Keltner Z, Nochetto CB, Black T, Olejnik N, Scott M, Bandele O, Nemser SM, Tkachenko A, et al. (2014). Reproductive toxicity in rats with crystal nephropathy following high doses of oral melamine or cyanuric acid. Food and Chemical Toxicology, 68: 142-153. Doi: 10.1016/j.fct.2014.02.029

Strakova E, Karaskova K, Zapletal D and Suchy P (2014). Effect of melamine and cyanurid acid contaminated diets on blood indicators in broiler chickens. Czech Journal of Animal Science, 59: 564-570. Doi: 10.17221/7796-cjas

Van Kampen EJ and Zijlstra WG (1961). Standardization of hemoglobinometry ii. The hemiglobincyanide method. Clinica Chimica Acta, 6 (4): 538-544. Doi: 10.1016/0009-8981(61)90145-0

Wilson JI, George BO and Umukoro GE (2011). Effects of honey on the histology of liver in adult wistar rats. Biology and Medicine, 3 (1): 1-5. Doi: 10.15406/mojbm.2017.02.00046

Xin H and Stone R (2008). Chinese probe unmasks high-tech adulteration with melamine. Science, 322 (5906): 1310-1311. Doi: $10.1126 /$ science.322.5906.1310

Yang J-L and Chen H-C (2003). Effects of gallium on common carp (cyprinus carpio): Acute test, serum biochemistry, and erythrocyte morphology. Chemosphere, 53 (8): 877-882. Doi: 10.1016/s0045-6535(03)00657-x

Yao L, Jiang Y, D'Arcy B, Singanusong R, Datta N, Caffin N and Raymont K (2004). Quantitative high-performance liquid chromatography analyses of flavonoids in australian eucalyptus honeys. Journal of Agricultural and Food Chemistry, 52 (2): 210-214. Doi: 10.1021/jf034990u

Yao LK, Razak SLA, Ismail N, Fai NC, Asgar MHAM, Sharif NM, Aan GJ and Jubri Z (2011). Malaysian gelam honey reduces oxidative damage and modulates antioxidant enzyme activities in young and middle aged rats. Journal of Medicinal Plants Research, 5 (23): 5618-5625. http://www.academicjournals.org/JMPR

Zhang L, Wu L-L, Wang Y-P, Liu A-M, Zou C-C and Zhao Z-Y (2009). Melamine-contaminated milk products induced urinary tract calculi in children. World Journal of Pediatrics, 5 (1): 31-35. Doi: 10.1007/s12519-009-0005-6

Zheng X, Zhao A, Xie G, Chi Y, Zhao L, Li H, Wang C, Bao Y, Jia W, Luther M, et al. (2013). Melamine-induced renal toxicity is mediated by the gut microbiota. Science translational medicine, 5 (172): 172ra22. Doi: 10.1126/scitranslmed.3005114

Zhou Y, Li C-Y, Li Y-S, Ren H-L, Lu S-Y, Tian X-L, Hao Y-M, Zhang Y-Y, Shen Q-F and Liu Z-S (2012). Monoclonal antibody based inhibition elisa as a new tool for the analysis of melamine in milk and pet food samples. Food Chemistry, 135 (4): 2681 2686. Doi: 10.1016/j.foodchem.2012.07.053 